IRA-International Journal of Management \& Social Sciences

ISSN 2455-2267; Vol.07, Issue 01 (2017)

Pg. no. 103-111

Institute of Research Advances

http://research-advances.org/index.php/RAJMSS

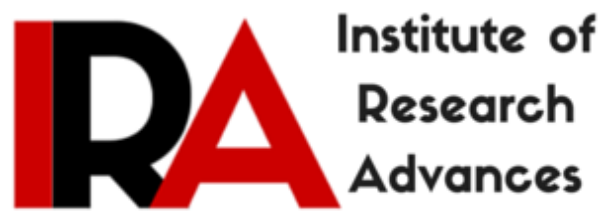

\title{
The HIV and AIDS Conversation: Who Are The Adolescents Talking To?
}

Sarah Moyo ${ }^{1}$, Shamiso Iline Chingombe ${ }^{2}$, Viola Ingwani $^{3}$, Loveness Chindanya $^{4}$

$\mathbf{1 , 2 , 3 , 4}$ Lecturer at Great Zimbabwe University, School of Education, Department of

Educational Foundations, Zimbabwe.

Type of Review: Peer Reviewed.

DOI: http://dx.doi.org/10.21013/jmss.v7.n1.p12

\section{How to cite this paper:}

Moyo, S., Chingombe, S., Ingwani, V., \& Chindanya, L. (2017). The HIV and AIDS Conversation:

Who Are The Adolescents Talking To?. IRA-International Journal of Management \& Social Sciences (ISSN 2455-2267), 7(1), 103-111. doi:http://dx.doi.org/10.21013/jmss.v7.n1.p12

(C) Institute of Research Advances

(cc) EY-NC

This work is licensed under a Creative Commons Attribution-Non Commercial 4.0 International License subject to proper citation to the publication source of the work.

Disclaimer: The scholarly papers as reviewed and published by the Institute of Research Advances (IRA) are the views and opinions of their respective authors and are not the views or opinions of the IRA. The IRA disclaims of any harm or loss caused due to the published content to any party. 


\section{ABSTRACT}

Healthy sexuality communication is critical in equipping adolescents with information and skills necessary in combating HIV and AIDS. This mixed method study sets to explore who the adolescents are talking to in regards to sex and HIV and AIDS in the Zimbabwean context. 147 secondary school learners (72 females and 75 males, age range 13 -20 years) were randomly sampled. Focus Group Discussions (FGDs) and questionnaires based on a 5 point Likert scale written on a continuum of SA-SD were employed to gather data. It was established that $36 \%$ adolescents feel free to discuss sex issues with family. Another $36 \%$ with friends, $14.9 \%$ with counselors and $12.1 \%$ put across that they were not free to discuss sex with anyone. In the FGDs most of the adolescents stated that they were more comfortable discussing sexuality issues with same sex parents. They indicated that conversations carried out with parents were largely centred on HIV and AIDS, puberty, abstinence and avoiding early sexual debut. Sexuality communication with peers was focused on condom use, contraceptives, abstinence, pregnancy, sexual intentions and sexual experiences. To promote healthy sexual behaviours among adolescents there is therefore need to craft programs and interventions that strengthen and improve the quality and content of sexuality dialogue with parents and peers.

Key words: HIV and AIDS, Adolescents, Sexuality Communication

\section{Introduction}

Globally, HIV and AIDS pandemic is a serious threat to humanity as a whole. In Zimbabwe as any other country in Sub - Saharan Africa, HIV and AIDS epidemic is reaching staggering proportions in all sectors of the society and across all age groups. Adolescents who are the window of hope are increasingly becoming more vulnerable. Prevailing economic situations, changes in the family structure, culturally defined gender inequalities and intergenerational sex are compounding the vulnerability of these young people. The challenge to the nation is how to maintain this window of hope in the war against HIV and AIDS. Aggleton and Rivers (2006) report that, it is estimated that half of all HIV infections worldwide have occurred among people under 25 years. HIV and AIDS in adolescents can have far- reaching consequences for all societies throughout the world, considering that approximately one-third of the world's population is between 10-24 years of age.

\section{Context and Justification}

A quarter of the world's population is made up of adolescents and young adults, meaning they make up a sizable proportion of the global population (UNFPA, 2012). More than 85\% of the global adolescent population is found in developing countries with more than one-third of the total population of subSaharan Africa aged 10-24 years (Blum \& Nelson-Mmari, 2004; UNFPA, 2012). The consequent dilemma of adolescent risk taking, especially sexual risk taking is disproportionately a problem in subSaharan Africa (Alhassan et al, 2014).

Focusing on young people has been recognized at global level by the 2001 United Nations General Assembly on HIV and AIDS. This Assembly endorsed a number of goals which included ensuring young men and women have access to information (United Nations General Assembly on HIV and AIDS, 2001). Such indications on a global scale are a major step towards reducing adolescent's vulnerability to HIV and

AIDS.

Adolescent is a stage marked by emotional upheavals due to hormonal changes taking place in their bodies. They experience fluctuations of moods, aggression, suffer identity crisis and storm and stress; they also face problems of generation gaps between them and adults. Aggleton and Rivers (2006) put forward that, it is popularly believed that all young people are risk-taking pleasure seekers who live only 
for the present. This view encourages a concept of adolescents as possessing a series of deficits. This is one of the most critical reasons why young people are denied access to information on sex and sexuality. Adults are therefore reluctant to impart information on sex, Sexually Transimitted Infections (STIs) and HIV / AIDS to these high risk human beings

In many societies, the family and the immediate community traditionally provided young people with information and guidance about sex and sexuality. Aggleton and Rivers (2006) observe that in many parts of the developing world, recent and rapid urbanization and migration have meant that families and community networks have become more widely dispersed. Rapid urbanization coupled with the increasing urban poverty in Sub -Saharan Africa may therefore expose more adolescents to risky sexual behaviors (Alhassan, et. al, 2014). This has an impact on sexual socialization of young people. Zimbabwe has not escaped this transition of rapid urbanization. According to Runganga and Aggleton (1998) extended family members including paternal aunts and uncles, are no longer available to offer advice to young women and young men, they lack guidance they used to receive from village elders. In their study, they comment that lack of communication in sex education within the family has led the young people to rely more on their peers for information on sex matters.

In a study carried out in Zimbabwe with 80 young people between 14-18 years (Wilson, et. al, 1994) noted that information from aunts and uncle was described by young people as generalized, one sided, authoritarian and prescriptive. The young people stated that credible sexual information was obtained from the media, school and friends.

In circumstances where open channels of communication are absent between families and adolescents, young people are placed in a vulnerable position. For instance, in a study in Kenya by Balmer, et. al (1997), the young people suggested that HIV and AIDS was a scare campaign perpetrated by older people to prevent them from enjoying sex. Such sentiments can only further expose teenagers to HIV infection. Some adults even have difficulties in acknowledging adolescents as sexual beings. Ultimately, young people are left to grope in the dark in search of information on sex, reproduction and HIV and AIDS.

To counter wrong sexual socialisation (Schenker 2004) proposes the "triangular model", a framework for developing and implementing HIV prevention education in families and in the communities.

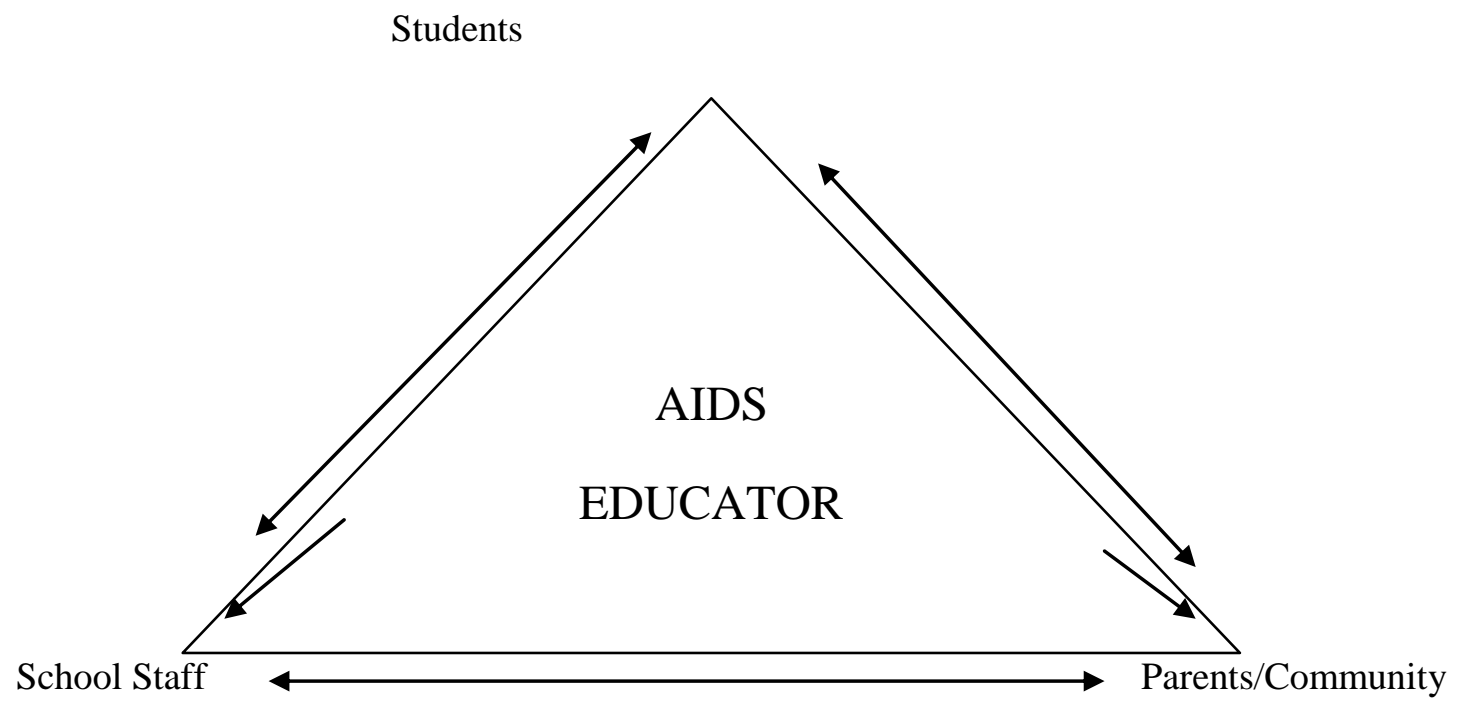

Figure (i) The triangular model

SOURCE: (SCHENKER 2004: 2) 
This model emphasizes on the well trained AIDS educator who can be a teacher, nurse, peer educator or a person living with HIV / AIDS. The role of the AIDS educator is to provide comprehensive education on HIV / AIDS to learners, school staff, parents and the community at large. This model is also believed to facilitate effective communication on HIV and AIDS among these groups of people. The key to containing the AIDS pandemic and to create an AIDS free generation seems to lie in the creation of a cultural and social environment that values the young people and sees them, as they really are - "the window of hope". Thus, if adolescents are exposed to the right environment, they can change the course of the epidemic.

Parents and families have sought to deny young people information about sex and reproduction believing this would incite them to irrationally engage in sexual experiments. Hoffman and Futterman (1996)observe that, "....adults often hold ambivalent attitudes towards young people, viewing them simultaneously as small adults and as immature inexperienced and untrustworthy children". Such views only further make adolescents more vulnerable to the AIDS causing virus because they do not seek to empower the youths.

With young people that make up almost half of the population in Zimbabwe providing a huge pool of the population moving into the sexually active range (Gudlanga et al, 2015). It is imperative that they receive intensive and adequate information on HIV/AIDS. Jackson (2002) notes that one of the limitations of the response to AIDS has been the failure by the youths to learn effectively from others. Educating the adolescents is a crucial investment for HIV prevention now and in the future.

In order to have a well informed generation of young people, it is of paramount importance to know who the adolescents are engaging in sexuality discussions as well as the quality and content of these conversations.

Davell and Ward (1999) also argue- that, since there is an average ten year time lag between the development of AIDS, most young adults diagnosed with AIDS become infected during adolescence. This makes the adolescent age group the prime time to be accessing and assessing the young people's current knowledge, attitudes and beliefs on HIV and AIDS. Conversations about HIV and AIDS and sexuality should be undertaken with the adolescents as a factor contributive to mitigating the effects of HIV and AIDS.

\section{Theoretical framework}

This study is premised on Urie Bronfenbrenner's ecological systems theory that places emphasis on the quality and context of the child's environment. Urie Bronfenbrenner's Ecological Systems Theory of Human Development (1979) examines the complex interactions and relationships between an individual and his/her multiple social and physical surroundings during adolescent development. Bronfenbrenner (1979) identifies four ecological systems: the microsystem, the mesosystem, the exosystem, and the macrosystem. More recently, Bronfenbrenner (1986) proposed an additional system, the chronosystem, which examines over time the influence of environmental changes on an individual's development.

The microsystem constitutes the immediate environment of the adolescents which includes family or peers. The mesosystem which interacts directly with the microsystem embodies the relationship between two or more settings, for example the relationship between the school and peers. The exosystem does not directly involve the adolescents but has impact on the life of the adolescents, for instance, the parent's workplace. Key components of the macrosystem include cultural and societal values, gender norms, bodies of knowledge, customs, material resources, opportunity structures, potential life-course trajectories, and the economic stability of the country in which one lives (Bronfenbrenner, 1979, 1989). 
The chronosystem focuses on transitions that occur across the lifespan such as puberty, entering the school system, death and divorce.

The Bronfenbrenner ecological systems theory lays stress on the quality and context of the child's surroundings (Harkonen, 2007). This theory thus provides a useful framework from which to explore the interrelations of adolescents and the different systems. Embedded in these are the people and contexts that are giving adolescents information on sexuality and HIV and AIDS. These dialogues are taking place in these ecological layers and their influences on adolescents' sexual behaviors are undoubtedly significant.

\section{Methodology}

Both quantitative and qualitative research designs were the main mixed methods used in this study. Both approaches were viewed as complementary rather than rival schools of thoughts. The territory of mixedmethod designs remains largely uncharted; of particular need is a clear differentiation of alternative purposes for mixing qualitative and quantitative methods. In this study we carefully and thoughtfully applied triangulation, hence specifying convergence type of mixed-methods. In triangulation we sought convergence, corroboration and correspondence of results from different methods. The use of both focus group discussions as a qualitative tool and questionnaire as a quantitative tool illustrates this triangulation, to "complement" (not as in embedded approach), the mixed methods approach, both in methodological underpinnings and data analysis. The sample participants comprised of 147 (72 males, 75 females, age range 13-20 years) school pupils randomly selected from 5 secondary schools out of 14 in Gweru urban and completed questionnaire for adolescents. Participants spanned throughout all strata of secondary level i.e. Forms 1 to 4 . School authorities assisted in stratified and systematic randomization.

Factor analysis, using Principal components with Varimax Rotation, Kaiser Normalisation and Scree testing, were used to determine validity and reliability coefficients of questionnaire and categorization of factors.

Variables with factor loading of 0.3 and above, Eigen values of 1 and above were considered for the main research study. The split half alpha reliability and Cronbach reliability was .65 and .63 respectively. This suggested adequate reliability of the 5 point Likert scale based on a continuum of SA-SD since the alpha and Cronbach values were relatively high enough.

Focus group discussions (FGDs) comprised 40 adolescents from two schools as a result of challenges which arose to gather all 147 participants from 5 schools.

The focus group discussion (FGD) started with a conversation between researchers and participants. Participants seemed motivated to engage in the discussion. The first few minutes of the (FGD) were on introductions and research objectives. The discussion was then centred on sexuality and HIV/AIDS matters. To avoid dominance, the participants took the lead while we listened, and jotted down notes, we audio-taped the discussion and gave necessary guidance. When we went back to our offices, we played the tapes several times, transcribed the discussion, categorised main issues and gave alphanumeric codes, and produced themes and subthemes.

Permission was granted by the Ministry of Education in writing to authorize us to visit schools. For ethical considerations, all participants were informed the objectives of the study. They were told that they were free to withdraw from the research at any time if they so wished. Participants' consent was sought in writing. Questionnaires were anonymously coded alpha-numerically. Confidentiality, anonymity and freedom to participate were granted. 


\section{Results}

In the questionnaire the adolescents were required to state who they feel free to converse with on sexuality issues. Most adolescents indicated that they felt at home talking to family and friends on sexuality and HIV and AIDS. The different responses are given in the graph below.

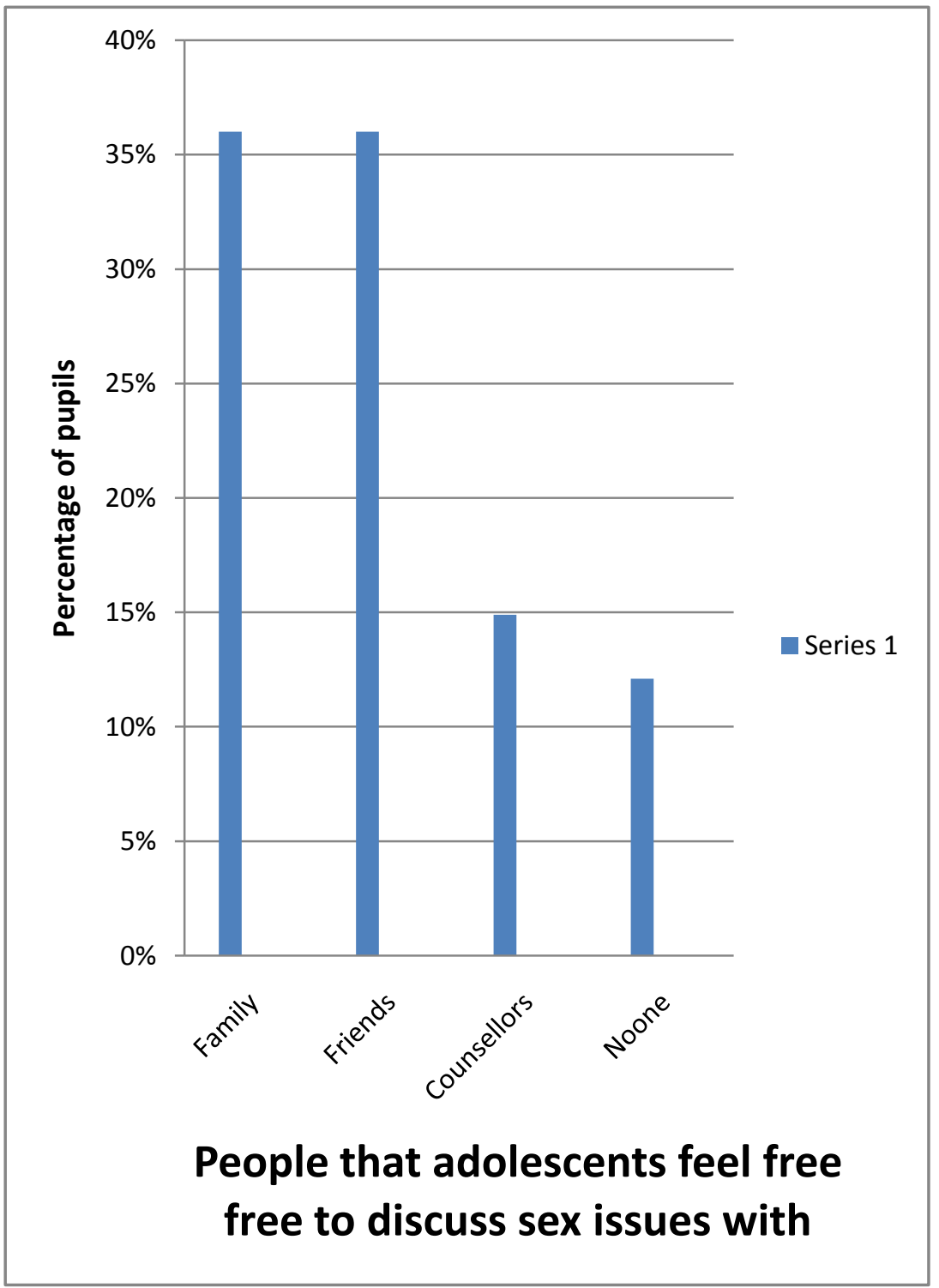

Fig (i): People which adolescents feel free to discuss sex issues with.

The graph establishes that $36 \%$ adolescents feel free to discuss sex issues with family. Another $36 \%$ with friends, $14.9 \%$ with counselors and $12.1 \%$ put across that they were not free to discuss sex with anyone. Within the family, parents $48 \%$ were the preferred confidantes in sexuality discussions. A $30 \%$ of the adolescents preferred siblings and $22 \%$ stated their preference to talk to aunts and uncles on sex issues.

During the FGDs several themes emerged. Same sex preference in sexuality communication was one such. Most girls identified their mothers and their female counter-parts as the ones they were most comfortable to talk to. On the other hand, similarly, most of the male adolescents preferred to converse 
with their fathers and male peers on issues of sexuality. A follow up on the content of these conversations during the FGDs revealed that discussions carried out with parents were largely centred on HIV and AIDS, puberty, abstinence and avoiding early sexual debut. On the other hand talks with siblings were largely premised on dating, relationships with opposite sex and sexual intentions. Sexuality communication with peers was focused on condom use, contraceptives, abstinence, pregnancy, sexual intentions and sexual experiences. These themes that emerged during the FGD are shown in Table 1 below.

\begin{tabular}{|c|c|}
\hline Parents & $\begin{array}{l}\text { Themes } \\
\text { - HIV and AIDS } \\
\text { - Puberty } \\
\text { - Abstinence } \\
\text { - Sexual debut }\end{array}$ \\
\hline Siblings & 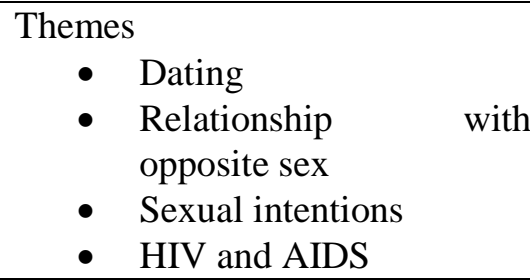 \\
\hline Peers & $\begin{array}{l}\text { Themes } \\
\text { - Condom use } \\
\text { - Contraceptives } \\
\text { - Pregnancy } \\
\text { - Sexual intentions } \\
\text { - Sexual experiences } \\
\text { - HIV and AIDS }\end{array}$ \\
\hline
\end{tabular}

Table 1: Emerging themes in the sexuality conversations with parents, siblings and peers.

\section{Discussion}

Friends and families were identified by the adolescents as the people they felt free to discuss sex related issues. McGlone et al (1996) cited in Gross (2005:542) stipulates that, young people "perceive family members as the most important significant others in their lives". However, the findings from this study revealed that the activities and programmes on HI V/AIDS carried out in the schools do not involve parents. Lyons (2003) argues that "circumstances of an individual's life and their social context in family during childhood can increase the probability they will one day be exposed to, and infected by HIV". Open sexual communication between parents and adolescents has been identified as protective factor that reduces sexual risk behavior by delaying onset of intercourse Commendador, 2010; Dilorio, Pluhar, \& Belcher, 2003; Jaccard, Dodge, \& Dittus, 2002; Widman et al, 2014; Motsomi et al, 2016; Ayalew etal 2014; Edwards and Reis, 2014; Juma et al ,2015). Engaging parents in sexual education of the adolescents, improving underlying beliefs and norms, and improve the adolescent-parent communication, self-disclosure and television co-viewing and discussions are essential( Dessie and Worku, 2015).Involvement of parents in the schools programmes on HIV /AIDS would improve the content and quality of their communications with adolescents. In turn, this would serve to decrease the young people's vulnerability to the virus.

Peer education has also been argued as having a positive effect. Hendry (1999) proposes that "peer and friendship groups can work in concert with, rather than in opposition to, adult goals and achievements". Schools would likely benefit from encouraging and mentoring peer educators in activities and 
programmes on HIV/AIDS (Gudlanga et al 2015). Gross (2005) further argues that "friendship groups or peer groups assume much greater significance during adolescence, such as helping to shape basic values, but these values are often consistent with parents' values, goals and achievements".

\section{Conclusion}

The promising and tentative results from the study that adolescents are talking to parents and peers on sexuality issues offer a window to give appropriate information and skills critically required in response to HIV/AIDS pandemic. Thus,programmes and interventions should be crafted to strengthen and improve the quality and content of sexuality dialogues among adolescents, family and peers. This is pivotal in promoting healthy and positive sexual behaviours in adolescents in the face of HIV and AIDS pandemic.

\section{Competing Interests}

All authors have declared that no competing interests exist.

\section{Author's contributions}

SM conceived the study, carried out the data collection and analysis, SC, VI and LC drafted the manuscript. All authors read and approved the final manuscript.

\section{References}

- Aggleton, P. \& Rivers, K. (2006). Adolescent Sexuality gender and the HIV epidemic. New York: Plenum publications.

- Ayalew, M., Mengistie, B., Semahegn, A (2014) Adolescent - parent communication on sexual and reproductive health issues among high school students in Dire Dawa, Eastern Ethiopia: a cross sectional study. Reproductive Health201411:77 doi: 10.1186/1742-4755-11-77

- Bronfenbrenner U. (1979). The ecology of human development: Experiments by nature and design. Cambridge, MA: Harvard University Press.

- Bronfenbrenner U. (1986). Ecology of the family as a context for human development: Research perspectives. Developmental Psychology. 1986;22:723-742. doi: 10.1037/0012-1649.22.6.72

- Commendador, K. A. (2010). Parental influences on adolescent decision making and contraceptive use. Pediatric Nursing, 36, 147-170.

- Dessie Y, Berhane Y, Worku A (2015) Parent-Adolescent Sexual and Reproductive Health Communication Is Very Limited and Associated with Adolescent Poor Behavioral Beliefs and Subjective Norms: Evidence from a Community Based Cross-Sectional Study in Eastern Ethiopia. PLoS ONE 10(7): e0129941. doi:10.1371/journal.pone.0129941

- Dilorio, C., Kelley, M., \& Hockenberry-Eaton, M. (1999). Communication about sexual issues: Mothers, fathers, and friends. Journal of Adolescent Health, 24, 181-189. doi:10.1016=S1054139X (98)00115-3

- Gross, R. (2005). Psychology. The Science of Mind and Behaviour $4^{\text {th }}$ ed. London: Greengate.

- Gudlanga, E.,Moyo S,. Gudlanga, A (2015) Navigating Sexuality and HIV/AIDS: Insights and Foresights of Zimbabwean AdolescentsBritish Journal of Education, Society \& Behavioural Science

- Hendry, L. B. (1999). Adolescents in Society. London: Jessica Kinsley.

- Jaccard, J., Dodge, T., \& Dittus, P. (2002). Parent-adolescent communication about sex and birth control: A conceptual framework. New Directions for Child and Adolescent Development, 97, 941. doi: $10.1002=\mathrm{cd} .48$ 
- Jackson, H. (2002). AIDS Africa: Continent in crisis. 1-Tarare: SAFAIDS.

- Juma M, Alaii J, Askew A, Bartholomew LK, Borne BVD (2015) Community Perspectives on Parental/Caregiver Communication on Reproductive Health and HIV with Adolescent Orphans and Non-Orphans in Western Kenya. J Child Adolesc Behav 3:206. doi: 10.4172/23754494.1000206

- Motsomi, K.,Makanjee, C.,Basera, T.,Nyasulu, P (2016) Factors affecting effective communication about sexual and reproductive health issues between parents and adolescents in zandspruit informal settlement, Johannesburg, South Africa The Pan African Medical Journal. 25:120.

- Schenker, I. (200.4). Education for HIVpreventjon Amsterdam: SAFAIDS.

- Widman, L., Choukas-Bradely, S.,Helms, S., Golin, C.,Prinsten, M. (2014). Sexual Communication Between Early Adolescents and Their Dating Partners, Parents, and Best Friends.Journal of sex Research, 51(7), 731-741, 2014. doi: 10.1080/00224499.2013.843148 